\title{
Analysing a cycling grand tour: Can we monitor fatigue with intensity or load ratios?
}

Citation for published version (APA):

Sanders, D., Heijboer, M., Hesselink, M. K. C., Myers, T., \& Akubat, I. (2018). Analysing a cycling grand tour: Can we monitor fatigue with intensity or load ratios? Journal of Sports Sciences, 36(12), 1385-1391. https://doi.org/10.1080/02640414.2017.1388669

Document status and date:

Published: 01/01/2018

DOI:

10.1080/02640414.2017.1388669

Document Version:

Publisher's PDF, also known as Version of record

Document license:

Taverne

\section{Please check the document version of this publication:}

- A submitted manuscript is the version of the article upon submission and before peer-review. There can be important differences between the submitted version and the official published version of record.

People interested in the research are advised to contact the author for the final version of the publication, or visit the DOI to the publisher's website.

- The final author version and the galley proof are versions of the publication after peer review.

- The final published version features the final layout of the paper including the volume, issue and page numbers.

Link to publication

\footnotetext{
General rights rights.

- You may freely distribute the URL identifying the publication in the public portal. please follow below link for the End User Agreement:

www.umlib.nl/taverne-license

Take down policy

If you believe that this document breaches copyright please contact us at:

repository@maastrichtuniversity.nl

providing details and we will investigate your claim.
}

Copyright and moral rights for the publications made accessible in the public portal are retained by the authors and/or other copyright owners and it is a condition of accessing publications that users recognise and abide by the legal requirements associated with these

- Users may download and print one copy of any publication from the public portal for the purpose of private study or research.

- You may not further distribute the material or use it for any profit-making activity or commercial gain

If the publication is distributed under the terms of Article $25 \mathrm{fa}$ of the Dutch Copyright Act, indicated by the "Taverne" license above, 


\title{
Analysing a cycling grand tour: Can we monitor fatigue with intensity or load ratios?
}

\author{
Dajo Sandersa, Mathieu Heijboer ${ }^{\mathrm{b}}$, Matthijs K. C. Hesselink ${ }^{c}$, Tony Myers ${ }^{\mathrm{a}}$ and Ibrahim Akubat ${ }^{\mathrm{a}}$
}

aSport, Physical Activity and Health Research Centre, Newman University, Birmingham, United Kingdom; 'b Sport Science, Team LottoNL-Jumbo Professional Cycling Team, Amsterdam, Netherlands; 'Department of Human Biology and Human Movement Science, NUTRIM School of Nutrition and Translational Research in Metabolism, MUMC+, Maastricht, Netherlands

\section{ABSTRACT}

This study evaluated the changes in ratios of different intensity (rating of perceived exertion; RPE, heart rate; HR, power output; PO) and load measures (session-RPE; SRPE, individualized TRIMP; iTRIMP, Training Stress Score ${ }^{\mathrm{TM}} ;$ TSS) in professional cyclists. RPE, PO and HR data was collected from twelve professional cyclists $\left(\mathrm{VO}_{2 \max } 75 \pm 6 \mathrm{ml} \cdot \mathrm{min} \cdot \mathrm{kg}^{-1}\right)$ during a two-week baseline training period and during two cycling Grand Tours. Subjective:objective intensity (RPE:HR, RPE:PO) and load (sRPE:iTRIMP, sRPE: TSS) ratios and external:internal intensity (PO:HR) and load (TSS:iTRIMP) ratios were calculated for every session. Moderate to large increases in the RPE:HR, RPE:PO and sRPE:TSS ratios $(d=0.79-1.79)$ and small increases in the PO:HR and SRPE:iTRIMP ratio $(d=0.21-0.41)$ were observed during Grand Tours compared to baseline training data. Differences in the TSS:iTRIMP ratio were trivial to small $(d=0.03-$ 0.27). Small to moderate week-to-week changes $(d=0.21-0.63)$ in the PO:HR, RPE:PO, RPE:HR, TSS: ITRIMP, sRPE:TTRIMP and sRPE:TSS were observed during the Grand Tour. Concluding, this study shows the value of using ratios of intensity and load measures in monitoring cyclists. Increases in ratios could reflect progressive fatigue that is not readily detected by changes in solitary intensity/load measures.
ARTICLE HISTORY

Accepted 29 September 2017

\section{KEYWORDS}

Training load; endurance; cycling; heart rate; power output

\section{Introduction}

A professional cyclist based in Europe will cycle around 30000 to 35000 kilometres in training and competition each year which will include about 90 to 100 competition days. A large fraction of professional cyclists participating in the World Tour participate in at least one, if not more, of the three week Grand Tours (Giro d'Italia, Tour de France, Vuelta a España) (Lucia, Hoyos, \& Chicharro, 2001). In the late nineties, the extreme physiological demands of these races became clear (Lucia, Hoyos, Carvajal, \& Chicharro, 1999). Further studies expanded upon this by evaluating the exercise load of the different Grand Tours (Lucia, Hoyos, Santalla, Earnest, \& Chicharro, 2003) and the intensity and load of different competition elements within Grand Tours (Padilla, Mujika, Orbananos, \& Angulo, 2000; Padilla et al., 2001; Padilla, Mujika, Santisteban, Impellizzeri, \& Goiriena, 2008).

Heart rate (HR) is the most used physiological measure to describe exercise intensity and load of road cycling competitions in sport science research (Achten \& Jeukendrup, 2003). The original Training Impulse (TRIMP) method proposed by Banister ("Banister's TRIMP"; bTRIMP) (Banister, 1991) was used by Padilla et al. (2000), Padilla et al. (2001), 2008) in a series of studies to evaluate exercise load of different competition elements in (mainly) Grand Tours. Lucia, Hoyos, Santalla, Earnest, and Chicarro (2003) calculated the exercise load of the Tour de France and Vuelta a España by calculating the time spent in three HR zones, with the ventilatory thresholds used as physiological landmarks to set these zones, and subsequently applied a weighting factor for each zone ("Lucia's TRIMP"; luTRIMP). These studies provided valuable insight in to the physical demands of professional cyclists competing in threeweek Grand Tours in terms of overall intensity and load characteristics and on the intensity and load of different competition elements. Recently, a study has suggested to use exercise load quantification methods that integrate individual physiological characteristics since they showed the highest doseresponse validity with changes in fitness and performance in competitive cyclists (Sanders, Abt, Hesselink, Myers, \& Akubat, 2017). In particular, the HR-based individualized TRIMP (iTRIMP) (Manzi, lellamo, Impellizzeri, D'Ottavio, \& Castagna, 2009) and the power output-based Training Stress Score ${ }^{T M}$ (Coggan, 2003) showed very large $(r=0.75-0.81)$ relationships with changes in aerobic fitness. There is, however, limited research available on using these measures in professional cycling to evaluate experienced load and/or fatigue progression while competing in a grand tour.

Rodríquez-Marroyo, Villa, García-Lopez, and Foster (2012) compared training load quantified by luTRIMP and session rating of perceived exertion (sRPE) analysing data from professional cyclists during three week Grand Tours. Interestingly, they showed an increasing slope in the relationships between SRPE and luTRIMP during the latter weeks of the Grand Tour. That is, for the same luTRIMP load in week 3 of the Grand Tour the SRPE load will substantially be higher compared to week 1 (Rodriguez-Marroyo

CONTACT Dajo Sanders dajosanders@gmail.com Physiology, Exercise \& Nutrition Research Group, Faculty of Health Sciences and Sport, Stirling University, Stirling, UK

Present address for Dajo Sanders is Physiology, Exercise \& Nutrition Research Group, Faculty of Health Sciences and Sport, Stirling University, Stirling, UK.

(c) 2017 Informa UK Limited, trading as Taylor \& Francis Group 
et al., 2012). Decreases in HR due to accumulated fatigue can be caused by a decreased sensitivity to catecholamines (Lehmann, Foster, Dickhuth, \& Gastmann, 1998) and an exhaustion of the adrenal and testes glands, which on previous occasions has been evident at the end of three week Grand Tours (Lucia et al., 2001). Therefore, in situations where the pattern of HR can be affected by accumulated fatigue, the integration of RPE and HR data could provide additional information on the fatigue state of the cyclist (Halson, 2014). That is, the same intensity in a fatigued state could potentially be perceived as harder, causing an increase in a ratio of RPE:HR compared to a "non-fatigued" state. However, there are no studies on the integration or ratios of these or other methods in detecting the fatigue state in competitive cyclists. Furthermore, the integration of an additional set of measures is also possible given the availability of mobile cycling power meters used by professional cyclists to monitor power output (PO) constantly during training and competition. Previous research has shown the effect of fatigue or increased training load on PO, HR and RPE responses and they highlight the importance of integrating multiple variables when monitoring athletes (Capostagno, Lambert, \& Lamberts, 2016; Lamberts, Rietjens, Tijdink, Noakes, \& Lambert, 2010). However, to the best of our knowledge studies evaluating the changes in ratios of intensity and load based on $\mathrm{RPE}, \mathrm{HR}$ and PO in professional cyclists during a Grand Tour, are currently lacking.

Subsequently, the present study used an integrated approach in evaluating intensity and load based on RPE, HR and PO during cycling Grand Tours as well as during a baseline training period preceding the Grand Tour competition. More specifically, we evaluated how and if ratios change during the latter stages of a Grand Tour and if this would provide additional information compared to solitary intensity or load measures.

\section{Methods}

\section{Participants}

Twelve participants (mean \pm SD), age $29 \pm 4.5$, body mass $72.2 \pm 5.3 \mathrm{~kg}, \mathrm{VO}_{2 \max }$ of $75 \pm 6 \mathrm{ml} \cdot \mathrm{min} \cdot \mathrm{kg}^{-1}$, were all part of the same UCI World-Tour professional cycling team. Institutional ethical approval was granted prior to commencing the study and in line with the declaration of Helsinki.

\section{Research design}

Data was collected during the 2016 Giro d'Italia and Vuelta a España. In the 2 weeks prior to the Grand Tours, training data was collected to obtain baseline training characteristics. Therefore, the main training characteristics of the baseline training data included taper strategies. The Grand Tours were split in to three weeks to provide week-to-week comparisons (week 1; stage 1-7, week 2; stage 8-14, week 3; stage 15-21) with rest day training sessions not included in the analysis.

\section{Physiological assessment}

Each participant performed a laboratory incremental test before the start of the competitive season (January). The test started at a workload of $2.50 \mathrm{~W} \cdot \mathrm{kg}^{-1}$ and increased with $0.50 \mathrm{~W} \cdot \mathrm{kg}^{-1}$ every 3 mins until exhaustion. Each cyclist performed the test on their own bicycle, which was placed on an ergometer (Cyclus2 ergometer, RBM Electronics, Leipzig, Germany). Gas exchange was measured continuously using a breath-by-breath gas analysis system (Metalyzer 3B, Cortex, Leipzig, Germany) and lactate measures were taken at the end of every 3 min stage and analysed directly using a portable lactate analyser (Lactate Pro, Arkray KDK, Japan). PO and $\mathrm{HR}$ at $2 \mathrm{mmol} \cdot \mathrm{L}^{-1}\left(\mathrm{LT}_{1}\right)$ and $4 \mathrm{mmol} \cdot \mathrm{L}^{-1}\left(\mathrm{LT}_{2}\right)$ lactate were calculated using publicly available software (Newell et al., 2007). These thresholds were also used to determine three intensity zones: zone $1, \leq \mathrm{LT}_{1}$; zone $2,>\mathrm{LT}_{1}$ and $<\mathrm{LT}_{2}$; zone 3 $\geq \mathrm{LT}_{2}$ (Seiler \& Kjerland, 2006). Intensity distribution around these zones was calculated to provide an additional descriptive measure of training and competition characteristics (Sanders, Myers, \& Akubat, 2017).

\section{Exercise load quantification}

Load was calculated using different methods based on either $\mathrm{HR}, \mathrm{PO}$ and RPE. HR and PO were continuously measured $(1 \mathrm{~Hz}$ ) during training and competition (Pioneer Power Meter, Kawasaki, Kanagawa, Japan). Riders were instructed to perform zero-offset procedures prior to each training session or stage according to manufacturers' instructions.

ITRIMP was calculated by weighting exercise intensity according to an individual's blood-lactate response to incremental exercise and weighting every $\mathrm{HR}$ rather than creating zones. An accumulated iTRIMP can then be calculated by summating the iTRIMP value for each HR data point collected. The individual weighting factor was calculated for each participant with the best-fitting method using exponential models as per the method of Manzi et al. (2009). As a subjective measure of internal load, sRPE was calculated based on the participants' RPE using the CR-10 scale proposed by Borg, Hassmen, and Lagerstrom (1987). The RPE was obtained $30 \mathrm{~min}$ after the exercise bout based on the question: "How hard was your workout?" Load of the session (sRPE) was subsequently quantified by multiplying the RPE by the duration of the session (minutes) (Foster, Daines, Hector, Snyder, \& Welsh, 1996).

A measure of external load the Training Stress Score ${ }^{\mathrm{TM}}$ (TSS) proposed by Coggan (2003) was measured using the following formula:

$$
T S S=[(t \times N P T M \times I F T M) /(F T P \times 3600)] \times 100
$$

where $t$ is the time, $N P^{T M}$ is normalized power (Coggan, 2003), $\mathrm{IF}^{\mathrm{TM}}$ is an intensity factor which is the ratio between the NP of the training session and the individual's FTP (Coggan, 2003) and FTP is the individual's functional threshold power. FTP was estimated based on the PO at $4 \mathrm{mmol} \cdot \mathrm{L}^{-1}$ lactate of the incremental lab test.

\section{Integration of intensity and load measures}

Based on the intensity (mean HR and PO and post-exercise RPE) and load (SRPE, iTRIMP and TSS) data of the baseline 
training period and the Grand Tours, multiple intensity and load ratios were calculated and evaluated including subjective: objective intensity (RPE:PO, RPE:HR) and load (sRPE:TSS, sRPE: iTRIMP) ratios and external:internal intensity (PO:HR) and load (TSS:ITRIMP) ratios. Based on previous literature (Lehmann et al., 1998; Lucia et al., 2001, 1999; Martin \& Andersen, 2000; Rodriguez-Marroyo et al., 2011, 2012) we expected an increase in the ratios to represent increased fatigue.

\section{Statistical analysis}

Descriptive results are presented as mean \pm standard deviation. Prior to analysis assumption of the normality of residuals was verified by visual inspection of $\mathrm{QQ}$ plots and using Shapiro-Wilk W test. Intensity, load variables and ratios were compared to each other using a multilevel random intercept model using Tukey's method for pairwise comparisons. The slope of the relationship between load variables (sRPE, iTRIMP, TSS) during different time periods (baseline; first, second and third week of Grand Tours) was performed using a leastsquares means analysis in R (R: A Language and environment for statistical computing, Vienna, Austria). Level of significance was established at $P<0.05$. In addition, magnitude based inferences was used to evaluate and describe the magnitude of the effects observed (Hopkins, Marshall, Batterham, \& Hanin, 2009). Standardised effect size is reported as Cohen's $d$, using the pooled standard deviation as the denominator. Qualitative interpretation of $d$ was based on the guidelines provided by Hopkins et al. (2009): 0-0.19 trivial; 0.20-0.59 small; 0.6-1.19 moderate; $1.20-1.99$ large; $\geq 2.00$ very large. Interpretation of the strength of the correlation coefficients were based on guidelines provided by Hopkins et al. (2009): 0-0.09 trivial; 0.1-0.29 small; $0.3-0.49$ moderate; $0.50-0.69$ large; $0.70-0.89$ very large; $0.90-0.99$ nearly perfect; 1.00 perfect.

\section{Results}

Nine datasets were analysed for the Giro d'Italia and eight datasets for the Vuelta a España with four participants competing in both of the Grand Tours. Early retirement in the Grand Tour due to crashes or illness resulted in four incomplete datasets but these were still included in the overall analysis. A total of 315 sessions were collected combining the baseline training period $(n=51)$ and data from the first $(n=84)$, second $(n=98)$ and third $(n=82)$ week of the Grand Tours. The results of the laboratory incremental cycling test are presented in Table 1.

\section{Intensity measures}

Duration, intensity and load measures during baseline training and the Grand Tours are presented in Table 2. A large to very large increase in RPE was observed during the Grand Tour compared to baseline training data $(d=1.42-2.00)$. There were small to moderate week-to-week increases $(d=0.22-0.78)$ observed in RPE in the second and third week of the Grand Tour. Duration, distance Mean PO and $\mathrm{NP}^{\mathrm{TM}}$ was small to moderately higher $(d=0.22-1.21)$ during the Grand Tour compared to baseline training data. Mean PO was moderately
Table 1. Physiological measures obtained from the laboratory incremental cycling test.

\begin{tabular}{lcc}
\hline $\mathrm{n}=12$ & Mean $\pm \mathrm{SD}$ & Range \\
\hline$\dot{\mathrm{VO}}$ & $75 \pm 6$ & $66-85$ \\
$\mathrm{VO}_{2 \max }\left(\mathrm{mL} \cdot \mathrm{min} \cdot \mathrm{kg}^{-1}\right)$ & $5.38 \pm 0.51$ & $4.58-6.12$ \\
$\mathrm{~W}_{\max }\left(\mathrm{W} \cdot \mathrm{min}^{-1}\right)$ & $423 \pm 31$ & $385-478$ \\
$\mathrm{HR}$ max $\left(\right.$ beats $\left.\cdot \mathrm{min}^{-1}\right)$ & $187 \pm 10$ & $168-201$ \\
$\mathrm{PO}$ at $2 \mathrm{mmol} \cdot \mathrm{L}^{-1}$ blood lactate $(\mathrm{W})$ & $323 \pm 27$ & $263-380$ \\
$\mathrm{PO}$ at $4 \mathrm{mmol} \cdot \mathrm{L}^{-1}$ blood lactate $(\mathrm{W})$ & $371 \pm 28$ & $322-429$ \\
$\mathrm{HR}$ at $2 \mathrm{mmol} \cdot \mathrm{L}^{-1}$ blood lactate (beats $\left.\cdot \mathrm{min}^{-1}\right)$ & $159 \pm 11$ & $140-176$ \\
$\mathrm{HR}$ at $4 \mathrm{mmol} \cdot \mathrm{L}^{-1}$ blood lactate (beats $\left.\cdot \mathrm{min}^{-1}\right)$ & $173 \pm 10$ & $156-188$ \\
\hline
\end{tabular}

Abbreviations: $\mathrm{VO}_{2 \max }$, maximal oxygen uptake; $\mathrm{W}_{\max }$ peak power output; $\mathrm{PO}$, power output; $\mathrm{HR}$, heart rate; $\mathrm{HR}_{\max }$, maximal heart rate.

Table 2. Duration, intensity and load of baseline training and grand tour data.

\begin{tabular}{|c|c|c|c|c|}
\hline & $\begin{array}{l}\text { Baseline } \\
\text { training } \\
(\mathrm{n}=51)\end{array}$ & $\begin{array}{l}\text { First week } \\
\quad \text { GT } \\
(\mathrm{n}=84)\end{array}$ & $\begin{array}{c}\text { Second week } \\
\text { GT } \\
(\mathrm{n}=98)\end{array}$ & $\begin{array}{l}\text { Third week GT } \\
\quad(\mathrm{n}=82)\end{array}$ \\
\hline Duration (min) & $187 \pm 106$ & $296 \pm 26^{\mathrm{a}}$ & $297 \pm 85^{a}$ & $248 \pm 91^{\mathrm{a}, \mathrm{b}}$ \\
\hline Distar & & & $180 \pm 43^{\mathrm{a}}$ & $148 \pm 59^{\mathrm{a}}$ \\
\hline RPE & 3. & $6.0 \pm$ & $7.0 \pm$ & $7.4 \pm 2.0^{\mathrm{a}, \mathrm{b}}$ \\
\hline Mean PO (W) & 201 & $208 \pm$ & $237 \pm$ & \\
\hline$N P(W)$ & $241=$ & $271 \pm 25^{\mathrm{a}}$ & $291 \pm 38^{\mathrm{a}, \mathrm{b}}$ & $43^{a, b}$ \\
\hline $\begin{array}{l}\% \text { PO zone } 1 \\
\text { (min) }\end{array}$ & $86.8=$ & 75.9 & 68.1 & $1.5^{\mathrm{a}, \mathrm{b}}$ \\
\hline $\begin{array}{l}\text { \% PO zone } 2 \\
\text { (min) }\end{array}$ & $5.9 \pm 5.6$ & $9.5 \pm 4.1$ & $11.2 \pm 5.0^{\mathrm{a}}$ & $12.9 \pm 11.7^{\mathrm{a}, \mathrm{b}}$ \\
\hline $\begin{array}{l}\text { \% PO zone } 3 \\
\text { (min) }\end{array}$ & $7.4 \pm 7.7$ & $14.7 \pm 4.0^{\mathrm{a}}$ & $20.7 \pm 11.1^{\mathrm{a}, \mathrm{b}}$ & $20.2 \pm 16.4^{\mathrm{a}}$ \\
\hline $\begin{array}{l}\text { Mean HR } \\
\quad \text { (beats.min }{ }^{-a} \text { ) }\end{array}$ & $124 \pm 13$ & $130 \pm 9$ & $130 \pm 11$ & $127 \pm 16$ \\
\hline $\begin{array}{l}\text { Mean HR \% } \\
\mathrm{HR}_{\max }\end{array}$ & 7 & 4 & 67 & $65 \pm 8$ \\
\hline $\begin{array}{l}\text { Maximal } \mathrm{HR} \\
\quad \text { (beats } \cdot \mathrm{min}^{-\mathrm{a}} \text { ) }\end{array}$ & $167 \pm 20$ & $181 \pm 7^{a}$ & $177 \pm 9^{a}$ & $174 \pm 9$ \\
\hline \multicolumn{5}{|l|}{ Mean training load } \\
\hline & $786 \pm 673$ & $1773 \pm 5$ & $2147 \pm 972^{\mathrm{a}, \mathrm{b}}$ & $1958 \pm 992^{\mathrm{a}}$ \\
\hline iTRIMP (AU) & & $292 \pm 1$ & $372 \pm 138^{\mathrm{a}}$ & $270 \pm 185^{\mathrm{a}}$ \\
\hline TSS (AU) & $155 \pm 104$ & $261 \pm 49^{\mathrm{a}}$ & $300 \pm 104^{\mathrm{a}, \mathrm{b}}$ & $223 \pm 111^{a, b, c}$ \\
\hline
\end{tabular}

Abbreviations: RPE, rating of perceived exertion; PO, power output; NP, Normalized Power ${ }^{\mathrm{Tm}}$, HR, heart rate; $\mathrm{HR}_{\text {max }}$ maximal heart rate; $\mathrm{SRPE}$, session rating of perceived exertion; iTRIMP, individualized TRIMP; TSS, Training Stress Score ${ }^{\mathrm{TM}}$.

${ }^{a}$ Significantly difference compared to baseline training data $(P<0.05)$

${ }^{\mathrm{b}}$ Significant difference compared to first week grand tour data $(P<0.05)$

c Significant difference compared to second week grand tour data $(P<0.05)$

higher in the second $(d=0.91)$ and third $(d=0.84)$ compared to the first week of the Grand Tour. A small decrease in mean HR was observed in week 3 compared to week $2(d=0.22)$. There were small week-to-week decreases in maximal HR $(d=0.33-0.50)$ during the Grand Tour. A greater proportion of PO in moderate (zone 2) and high-intensity (zone 3 ) ranges was observed in the Grand Tour compared to baseline training data and when comparing week 2 and week 3 to week 1 (Table 2).

\section{Load measures}

Exercise load measured with SRPE and TSS was moderately to largely higher during the Grand Tour compared to baseline training data ( $d=0.63-1.68)$, whilst small to moderately higher iTRIMP loads were observed when comparing the Grand Tour to baseline training data $(d=0.33-1.03)$. Load was moderately higher in the second week of the Grand Tour compared to week 1 and 3 for TSS 
$(d=1.05,0.71)$ and iTRIMP $(d=0.66,0.63)$. SRPE was also higher in the second week of the Grand Tour but these differences were small and trivial compared to week $1(d=0.51)$ and week 3 $(d=0.19)$.

The increases in the slope of linear relationship between SRPE and TSS and SRPE and iTRIMP are presented in Figure 1. The relationship between SRPE and TSS was nearly perfect during baseline ( $r=0.91,[95 \% \mathrm{Cl}: 0.84$ to 0.95$], \mathrm{n}=48)$ and very strong for week $1(r=0.62$, [95\% Cl: 0.42 to 0.74$], \mathrm{n}=77)$, week 2 ( $r=0.80$, [95\% Cl: 0.71 to 0.87 ], $\mathrm{n}=85$ ) and week 3 ( $r=0.87$, [95\% Cl: 0.78 to 0.92$], n=51$ ) of the Grand Tour. The relationship between SRPE and iTRIMP was very strong during baseline $(r=0.72,[95 \% \mathrm{Cl}: 0.53$ to 0.84$], \mathrm{n}=40)$, week 2 $(r=0.86,[95 \% \mathrm{Cl}: 0.70$ to 0.94$], \mathrm{n}=24)$ and week $3(r=0.88$, [95\% Cl: 0.67 to 0.96$], \mathrm{n}=15$ ) and moderate during week 1 $(r=0.43,[95 \% \mathrm{Cl}: 0.08$ to 0.69$], \mathrm{n}=29)$.

\section{Intensity ratios}

Large increases were observed when comparing the RPE:HR ratio during the Grand Tour to baseline $(d=1.22-1.79)$ (Table 3). A moderate $(d=0.62)$ and small $(d=0.47)$ increase was observed in week 2 and 3 of the Grand Tour compared to week 1 , whilst the change from week 2 to week 3 was trivial $(d=0.09)$ (Figure 2A). There were moderate to large increases in RPE:PO ratios observed during the Grand Tour $(d=0.79$ 1.48) when compared to baseline training (Figure $2 \mathrm{~A}$ ). A small difference $(d=0.31)$ was observed between the first and third
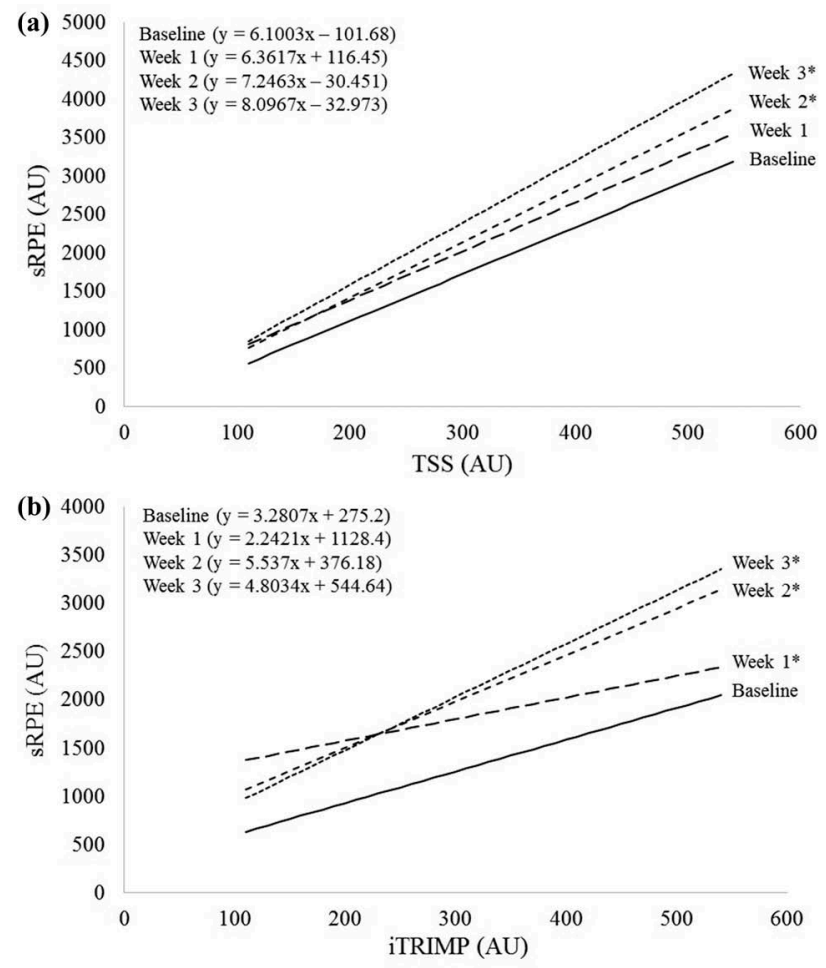

Figure 1. Regression lines comparing the relationship between TSS (a) and iTRIMP (b) versus SRPE based training load during the baseline training period and the first, second and third week of the cycling grand tours.

$\mathrm{AU}=$ arbitrary units; SRPE = session rating of perceived exertion; TSS = Training stress score $^{\mathrm{TM}}$; iTRIMP $=$ individualized training impulse. ${ }^{*}$ Significantly difference compared to baseline training data $(P<0.05)$.
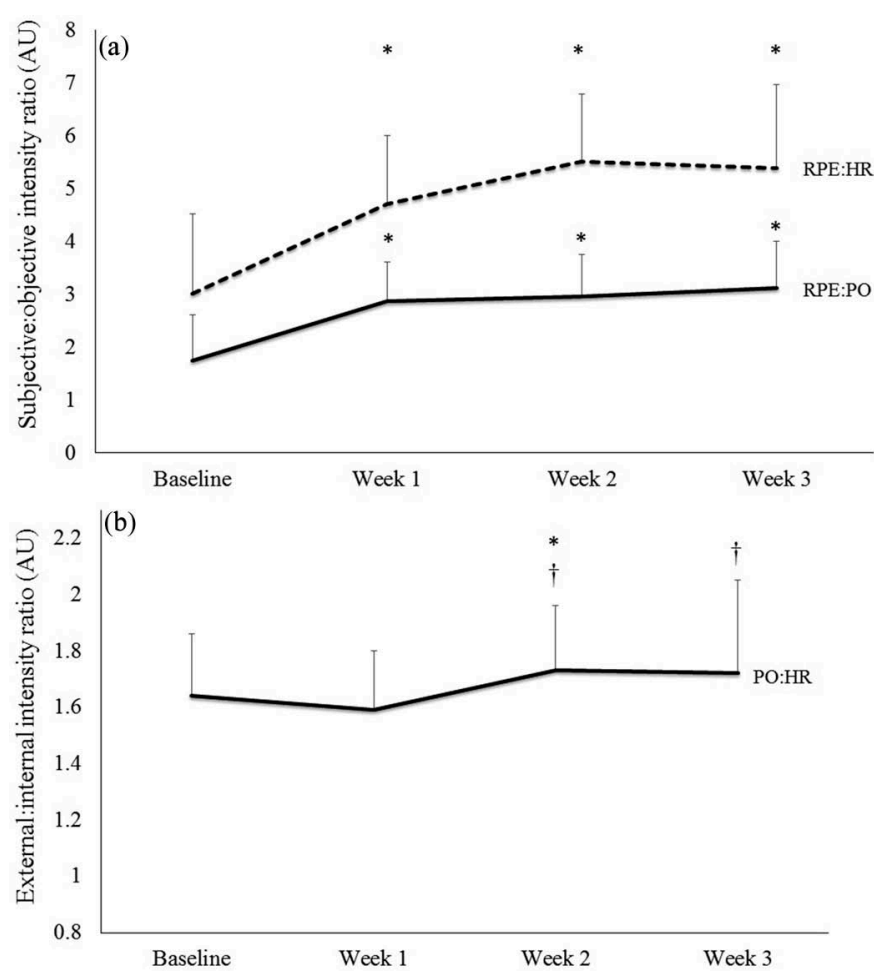

Figure 2. Subjective:objective intensity ratios (a) including the RPE:HR and RPE: $\mathrm{PO}$ ratio and the external:internal intensity ratio (b) including the PO:HR ratio during baseline training data and three weeks of a grand tour.

* Significantly different from baseline training data $(P<0.05)$. $†$ Significantly different from week $1(P<0.05)$. RPE = rating of perceived exertion; $\mathrm{HR}=$ heart rate; $\mathrm{PO}=$ power output.

week of the Grand Tour whilst other between-week comparisons were trivial $(d=0.12-0.19)$. Small differences were observed in the mean PO:HR ratio between baseline training and Grand Tour data ( $d=0.23-0.38$ ) (Figure 2B). A moderate decrease was observed comparing week 1 and week 2 of the Grand Tour $(d=0.61)$ whilst there was a trivial change from week 2 to week $3(d=0.01)$.

\section{Load ratios}

The SRPE:TSS ratio was moderately higher $(d=0.91-1.17)$ during the Grand Tour (Figure 3(a)) compared to baseline training. A small difference was observed when comparing week 3 with week 1 $(d=0.49)$ and week $2(d=0.34)$ of the Grand Tour. For the sRPE: iTRIMP we observed small increases in the Grand Tour compared to baseline training data $(d=0.21-0.41)$ (Figure $3(b))$. During the Grand Tour, we observed a trivial increase in the second week compared to the first week $(d=0.14)$ and small increase when comparing the third to second week $(d=0.28)$. Trivial to small increases in the TSS:TRIMP ratio were observed when comparing the Grand Tours to baseline $(d=0.03-0.27)$. Small increases were observed comparing week 3 to week $1(d=0.25)$ and week 2 $(d=0.39)$.

\section{Discussion}

This study examined if ratios of intensity and load based on RPE, $\mathrm{HR}$ and PO data during cycling training and competition would provide different or additional information compared to solitary 
Table 3. Intensity and load ratios of baseline training data and during the grand tour.

\begin{tabular}{|c|c|c|c|c|c|c|c|c|c|c|}
\hline & \multirow[b]{2}{*}{ Baseline } & \multicolumn{3}{|c|}{ Grand Tour } & \multicolumn{6}{|c|}{ Pairwise comparisons } \\
\hline & & Week 1 & Week 2 & Week 3 & $\begin{array}{c}\text { Baseline vs } \\
\text { Week } 1\end{array}$ & $\begin{array}{l}\text { Baseline vs } \\
\text { Week } 2\end{array}$ & $\begin{array}{l}\text { Baseline vs } \\
\text { week } 3\end{array}$ & $\begin{array}{c}\text { Week } 1 \text { vs } \\
\text { Week } 2\end{array}$ & $\begin{array}{l}\text { Week } 1 \text { vs } \\
\text { Week } 3\end{array}$ & $\begin{array}{c}\text { Week } 2 \text { vs } \\
\text { week } 3\end{array}$ \\
\hline \multicolumn{11}{|l|}{ Intensity ratio } \\
\hline \multicolumn{11}{|l|}{ Load ratio } \\
\hline
\end{tabular}

Abbreviations: RPE, rating of perceived exertion; PO, power output; HR, heart rate; sRPE, session rating of perceived exertion; iTRIMP, individualized TRIMP; TSS, Training Stress Score ${ }^{\mathrm{TM}}$.

a Significantly difference compared to baseline training data $(P<0.05)$

${ }^{b}$ Significant difference compared to first week grand tour data $(P<0.05)$

c Significant difference compared to second week grand tour data $(P<0.05)$

intensity and load measures. This study revealed that exercise intensity and load was moderately to largely higher during the Grand Tour compared to baseline training. In addition, we observed week-to-week increases in RPE and mean power output but decreases in mean and maximal HR within the Grand Tour. Additionally, the study showed moderate to large increases in the subjective:objective intensity (RPE:HR, RPE:PO) and load (sRPE:TSS,
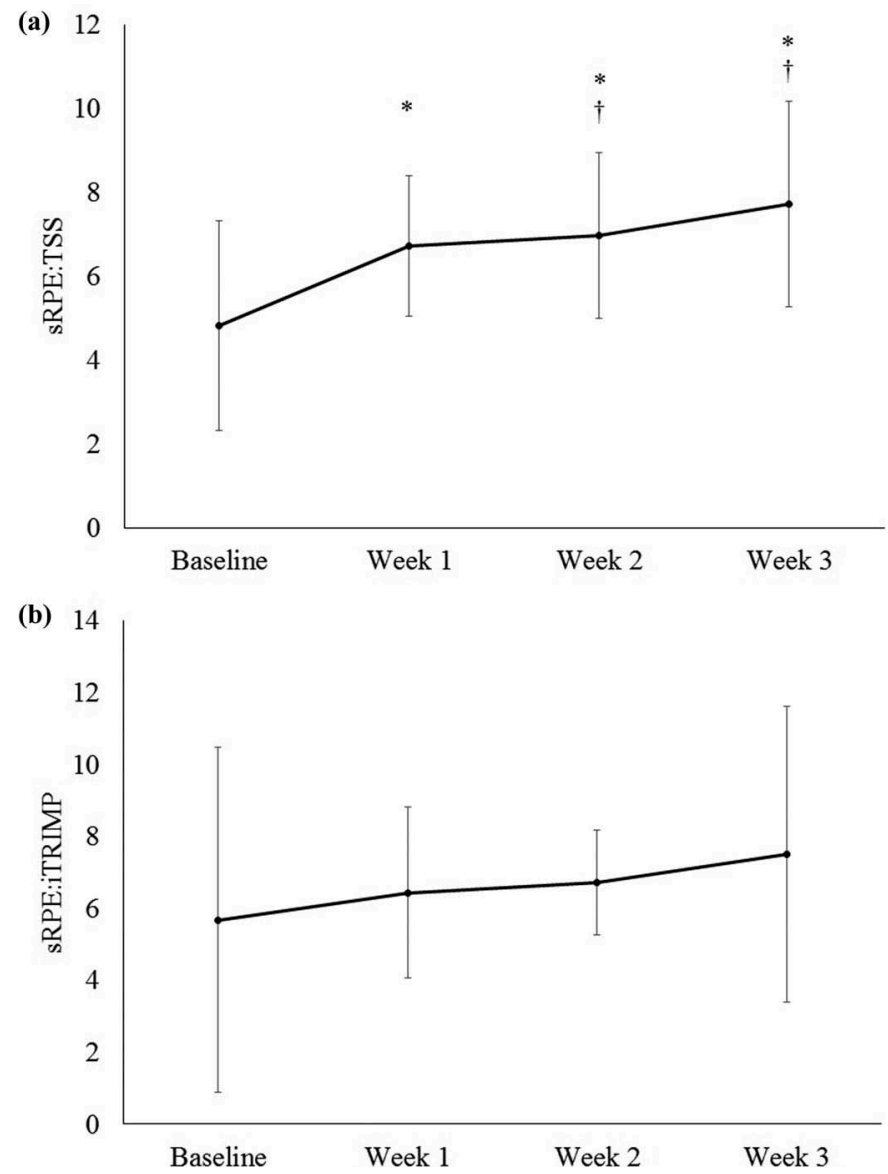

Figure 3. sRPE:TSS ratio (a) and sRPE:ITRIMP ratio (b) during baseline training and grand tour data.

*Significantly different from baseline training data $(P<0.05)$. + Significantly different from week $1(P<0.05)$. sRPE $=$ session rating of perceived exertion training load; TSS $=$ Training stress score $^{\mathrm{TM}}$; iTRIMP $=$ individualized TRIMP.
sRPE:TTRIMP) ratios in the Grand Tours compared to baseline training data. During the Grand Tours, there were no clear decreasing or increasing trends observed in load quantified using SRPE, TSS and iTRIMP over the course of the Grand Tours with load being highest in the second week for all three measures. Potential factors relating to the higher load in the second week can include race tactics or strategy and course profile (e.g., more elevation gain) (Lucia et al., 1999, 2001). However, when expressed as a ratio, small to moderate week-to-week continuous increases in the SRPE:TSS and SRPE:iTRIMP ratios were observed during the Grand Tours. Accumulated fatigue caused by the demanding nature of Grand Tours most likely contributes to the gradual increase in these ratios. Changes in ratios were not reflected in solitary load measures suggesting that they can provide valuable additional information when monitoring athletes.

Similar to the results of Rodriquez-Marroyo et al. (2012), we showed that the slope of the linear relationship between SRPE and iTRIMP increasing during the second and third week of the Grand Tours. Contributing to these results is the increased perceived intensity (RPE) but decreased internal intensity (HR response). Decreases in HR due to the accumulated load can be caused by a decreased sensitivity to catecholamines (Lehmann et al., 1998) and an exhaustion of the adrenal and testes glands, which has previously been shown to become evident at the end of three week Grand Tours (Lucia et al., 2001). This was also reflected in the increasing RPE:HR ratio compared to baseline training data and the small to moderate increases during the first, second and third week of the Grand Tours. Similar results were obtained with the RPE:PO ratio. Based on the assumption that the cyclists are more fatigued in the final few stages of a Grand Tour compared to the first week, these results show the potential use of the RPE:HR and RPE:PO ratio to detect the fatigue state of cyclists during a Grand Tour over intensity and load measures alone. This is line with the study by Martin and Andersen (2000) who suggested that a ratio of RPE and HR may be a practical measure for monitoring an aspect of fatigue associated with high-intensity training. Furthermore, this is in line with previous research highlighting the importance of including multiple variables (RPE, $\mathrm{PO}, \mathrm{HR}$ ) when monitoring the adaptation or fatigue process of athletes instead of evaluating one variable in isolation (Capostagno et al., 2016; Lamberts et al., 2010; Mann, Platt, Lamberts, \& Lambert, 2015). 
When evaluating the regressions of SRPE and TSS, similar to the relationships of SRPE and ITRIMP, we observed an increasing slope of the linear relationship during the latter weeks of the Grand Tours. Based on these regressions, a TSS score of $300 \mathrm{AU}$ will induce a sRPE load of $2025 \mathrm{AU}$ in the first week of the Grand Tours and $2396 \mathrm{AU}$ in the third week of the Grand Tours, a difference of $\sim 17 \%$. This was further substantiated by the small to moderate increases in the sRPE:TSS ratio when comparing week 1 vs week 2 vs week 3 of the Grand Tours. In contrary, the increases in the SRPE:ITRIMP ratios during the Grand Tours were trivial to small. One should note that the SRPE:iTRIMP ratio also showed a substantial higher standard deviation compared to the SRPE:TSS ratio. Based on these results, the sRPE:TSS ratio should be considered favourable due to lower variability in the ratio. In addition, it must be noted that the sample size of the SRPE:ITRIMP ratio was substantially lower for the first $(n=29)$, second $(n=24)$ and third week ( $n=15$ ) of the Grand Tour compared to sRPE:TSS ( $n=77$, 85 and 51, respectively). This is explained by the fact that in some instances the HR belt was not worn by the cyclist, either in competition or baseline training, which resulted in only power data to be analysed for these exercise bouts.

We reported a plateau in the subjective:objective intensity ratios (RPE:HR, RPE:PO) in the last week of the Grand Tours with trivial changes in these ratios in the last 2 weeks of the Grand Tours. In contrast, the subjective:objective load ratios (sRPE:TSS, sRPE:ITRIMP) showed continuous increase over the course of the Grand Tours including a small increase from week 2 to week 3 . This suggests that the inclusion of volume, which is integrated in load measurements, may result in additional information and continuous increases during the latter stages of a Grand Tour compared to intensity ratios which do not account for volume. Especially in competitive settings like a Grand Tour, where the duration of stages can vary substantially (Lucia et al., 2001), the inclusion of volume seems to be essential to fully account for variability in stage duration.

We observed small increases $(d=0.23-0.37)$ in the PO: $\mathrm{HR}$ ratio during a Grand Tour compared to baseline and a moderate increase from comparing the second to first week in the Grand Tour suggesting that such an intensity ratio might provide additional information compared to solitary HR or PO measures. However, ratios between a subjectively perceived load (SRPE) and HR or PO-based load (iTRIMP, TSS) seem to be more favourable measures compared to TSS:iTRIMP ratios. Even though an increasing trend was observed in the mean TSS:iTRIMP ratio during the Grand Tours, these differences were much smaller $(d=0.03-0.19)$ compared to the subjective:objective ratios. Therefore, decreases in HR due to accumulated fatigue in a Grand Tour are not substantial enough to induce substantial increases in the TSS:ITRIMP ratio and therefore limits the potential use of this ratio as a marker of fatigue. That is, SRPE seems to be more sensitive to increase in states of fatigue during periods of high training loads and may therefore be considered more valuable to include in ratios to monitor fatigue.

One limitation of this study is that the testing was conducted before the start of the competitive season and there might be some changes in physiological capacity between the time of the testing and the data collection that might influence load calculations. However, since the margin of improvement is smaller in these highly trained athletes this is somewhat mitigated. In addition, even though it is reasonable to assume that the cyclists are in a fatigued state at the end of a Grand Tour (Lucia et al., 2001), due to the hectic nature of a Grand Tour cycling race, it was not feasible in our study to include any additional physiological or psychological indicators of fatigue. Furthermore, FTP is typically defined as the maximal PO that can be sustained over 45-60min and is typically assessed using field-based time trials (Coggan, 2003). It must be acknowledged that a specific field-based assessment of FTP was not included, but estimated using the laboratory test results, which increases the potential of measurement errors with regards to TSS and related ratios (Sanders, Taylor, Myers, \& Akubat, 2017). Lastly, due to the use of a taper period in baseline training, residual fatigue was diminished providing an ideal scenario to measure changes in ratios comparing a rested state (baseline) to a fatigued state (Grand Tour). It remains to be elucidated how and if the proposed ratios of this study change during other training phases (e.g., preparatory phases without competitions) where the changes in load aren't as drastic. Future research should evaluate the use of intensity and load ratios during the daily training process to monitor the fatigue state.

\section{Conclusions}

To conclude, this study is the first to show the changes in intensity and load ratios during a Grand Tour in professional cyclists. Changes observed in ratios were not reflected in solitary load measures suggesting that ratios can provide valuable additional information when monitoring athletes. This study shows the potential of an external:internal intensity (PO:HR) ratio, ratios between perceptual and physiological indicators of intensity (RPE:HR) and load (sRPE:iTRIMP) and ratios between perceptual and external intensity (RPE:PO) and load (sRPE:TSS) to monitor the fatigue state of cyclists.

\section{Acknowledgements}

The authors would like to thank Melvin Kantebeen for his work collecting the data of the laboratory testing. Furthermore, we would like to thank the cyclists for their participation in this investigation.

\section{Disclosure statement}

No potential conflict of interest was reported by the authors.

\section{Funding}

No sources of funding were used for this study.

\section{References}

Achten, J., \& Jeukendrup, A. E. (2003). Heart rate monitoring: Applications and limitations. Sports Medicine, 33(7), 517-538. doi:10.2165/00007256200333070-00004 
Banister, E. W. (1991). Modeling elite athletic performance. In J. D. Macdouggal, H. A. Wenger, \& H. J. Green (Eds.), Physiological testing of elite athletes (pp. 403-422). Champaign, Illinois: Human Kinetics.

Borg, G., Hassmen, P., \& Lagerstrom, M. (1987). Perceived exertion related to heart rate and blood lactate during arm and leg exercise. European Journal of Applied Physiology and Occupational Physiology, 56(6), 679685. doi:10.1007/BF00424810

Capostagno, B., Lambert, M. I., \& Lamberts, R. P. (2016). A systematic review of submaximal cycle tests to predict, monitor, and optimize cycling performance. International Journal of Sports Physiology and Performance, 11(6), 707-714. doi:10.1123/ijspp.2016-0174

Coggan, A. R. (2003). Training and racing using a power meter: An introduction. In Level II coaching manual (pp. 123-145). Colorado Springs, CO: USA Cycling.

Foster, C., Daines, E., Hector, L., Snyder, A. C., \& Welsh, R. (1996). Athletic performance in relation to training load. Wisconsin Medical Journal, 95 (6), 370-374.

Halson, S. L. (2014). Monitoring training load to understand fatigue in athletes. Sports Medicine, 44(Suppl 2), S139-147. doi:10.1007/s40279014-0253-z

Hopkins, W. G., Marshall, S. W., Batterham, A. M., \& Hanin, J. (2009) Progressive statistics for studies in sports medicine and exercise science. Medicine and Science in Sports and Exercise, 41(1), 3-13. doi:10.1249/MSS.0b013e31818cb278

Lamberts, R. P., Rietjens, G. J., Tijdink, H. H., Noakes, T. D., \& Lambert, M. I. (2010). Measuring submaximal performance parameters to monitor fatigue and predict cycling performance: A case study of a worldclass cyclo-cross cyclist. European Journal of Applied Physiology, 108(1), 183-190. doi:10.1007/s00421-009-1291-3

Lehmann, M., Foster, C., Dickhuth, H. H., \& Gastmann, U. (1998). Autonomic imbalance hypothesis and overtraining syndrome. Medicine and Science in Sports and Exercise, 30(7), 1140-1145. doi:10.1097/00005768199807000-00019

Lucia, A., Diaz, B., Hoyos, J., Fernandez, C., Villa, G., Bandres, F., \& Chicharro, J. L. (2001). Hormone levels of world class cyclists during the tour of Spain stage race. British Journal of Sports Medicine, 35(6), 424-430. doi:10.1136/bjsm.35.6.424

Lucia, A., Hoyos, J., Carvajal, A., \& Chicharro, J. L. (1999). Heart rate response to professional road cycling: The tour de France. International Journal of Sports Medicine, 20(3), 167-172. doi:10.1055/s-1999-970284

Lucia, A., Hoyos, J., \& Chicharro, J. L. (2001). Physiology of professional road cycling. Sports Medicine, 31(5), 325-337. doi:10.2165/00007256200131050-00004

Lucia, A., Hoyos, J., Santalla, A., Earnest, C., \& Chicharro, J. L. (2003). Tour de France versus vuelta a espana: Which is harder? Medicine and Science in Sports and Exercise, 35(5), 872-878. doi:10.1249/01. MSS.0000064999.82036.B4

Mann, T. N., Platt, C. E., Lamberts, R. P., \& Lambert, M. I. (2015). Faster heart rate recovery with increased RPE: Paradoxical responses after an $87-\mathrm{km}$ ultramarathon. Journal of Strength and Conditioning Research/National Strength \&
Conditioning Association, 29(12), 3343-3352. doi:10.1519/ JSC.0000000000001004

Manzi, V., lellamo, F., Impellizzeri, F., D'Ottavio, S., \& Castagna, C. (2009). Relation between individualized training impulses and performance in distance runners. Medicine and Science in Sports and Exercise, 41(11), 2090-2096. doi:10.1249/MSS.0b013e3181a6a959

Martin, D. T., \& Andersen, M. B. (2000). Heart rate-perceived exertion relationship during training and taper. The Journal of Sports Medicine and Physical Fitness, 40(3), 201-208.

Newell, J., Higgins, D., Madden, N., Cruickshank, J., Einbeck, J., McMillan, K., \& McDonald, R. (2007). Software for calculating blood lactate endurance markers. Journal of Sports Sciences, 25(12), 1403-1409. doi:10.1080/02640410601128922

Padilla, S., Mujika, I., Orbananos, J., \& Angulo, F. (2000). Exercise intensity during competition time trials in professional road cycling. Medicine and Science in Sports and Exercise, 32(4), 850-856. doi:10.1097/00005768200004000-00019

Padilla, S., Mujika, I., Orbananos, J., Santisteban, J., Angulo, F., \& Jose Goiriena, J. (2001). Exercise intensity and load during mass-start stage races in professional road cycling. Medicine and Science in Sports and Exercise, 33(5), 796-802. doi:10.1097/00005768-200105000-00019

Padilla, S., Mujika, I., Santisteban, J., Impellizzeri, F. M., \& Goiriena, J. J. (2008). Exercise intensity and load during uphill cycling in professional 3-week races. European Journal of Applied Physiology, 102(4), 431-438. doi:10.1007/s00421-007-0602-9

Rodriguez-Marroyo, J. A., Pernia, R., Cejuela, R., Garcia-Lopez, J., Llopis, J., \& Villa, J. G. (2011). Exercise intensity and load during different races in youth and junior cyclists. Journal of Strength and Conditioning Research/ National Strength \& Conditioning Association, 25(2), 511-519. doi:10.1519/JSC.0b013e3181bf4426

Rodriguez-Marroyo, J. A., Villa, G., Garcia-Lopez, J., \& Foster, C. (2012). Comparison of heart rate and session rating of perceived exertion methods of defining exercise load in cyclists. Journal of Strength and Conditioning Research/National Strength \& Conditioning Association, 26 (8), 2249-2257. doi:10.1519/JSC.0b013e31823a4233

Sanders, D., Abt, G., Hesselink, M. K., Myers, T., \& Akubat, I. (2017). Methods of monitoring training load and their relationships to changes in fitness and performance in competitive road cyclists. International Journal of Sports Physiology and Performance, 1-23. doi:10.1123/ijspp.2016-0454

Sanders, D., Myers, T., \& Akubat, I. (2017). Training intensity distribution in road cyclists: Objective versus subjective measures. International Journal of Sports Physiology and Performance, 1-20. doi:10.1123/ijspp.2016-0523

Sanders, D., Taylor, R. J., Myers, T., \& Akubat, I. (2017). A field-based cycling test to assess predictors of endurance performance and establishing training zones. Journal of Strength and Conditioning Research/National Strength \& Conditioning Association. doi:10.1519/JSC.0000000000001910

Seiler, S., \& Kjerland, G. O. (2006). Quantifying training intensity distribution in elite endurance athletes: Is there evidence for an "optimal" distribution? Scandinavian Journal of Medicine \& Science in Sports, 16(1), 49-56. doi:10.1111/j.1600-0838.2004.00418.x 